\title{
Recognizing and managing the expanded risk of tumor lysis syndrome in hematologic and solid malignancies
}

\author{
Ali McBride ${ }^{1^{*}}$ and Peter Westervelt ${ }^{2}$
}

\begin{abstract}
Tumor lysis syndrome (TLS) is widely recognized as a serious adverse event associated with the cytotoxic therapies primarily used in hematologic cancers, such as Burkitt lymphoma and acute lymphoblastic leukemia. In recent years, TLS has been more widely observed, due at least in part to the availability of more effective cancer treatments. Moreover, TLS is seen with greater frequency in solid tumors, and particularly in bulky tumors with extensive metastases and tumors with organ or bone marrow involvement. The consequences of TLS include the serious morbidity and high risk of mortality associated with the condition itself. Additionally, TLS may delay or force an alteration in the patient's chemotherapy regimen. The changing patterns of TLS, as well as its frequency, in the clinical setting, result in unnecessarily high rates of illness and/or fatality. Prophylactic measures are widely available for patients at risk of TLS, and are considered highly effective. The present article discusses the various manifestations of TLS, its risk factors and management options to prevent TLS from occurring.
\end{abstract}

Keywords: Acute renal failure, Allopurinol, Adverse events, Hematologic malignancies, Management, Prophylactic therapy, Solid tumors, Tumor lysis syndrome (TLS), Rasburicase, Uric acid

\section{Introduction}

In recent years, tumor lysis syndrome (TLS), an oncologic emergency typically associated with cytotoxic therapies, is more likely to be seen across a spectrum of cancer types [1-3]. Previously regarded as a risk primarily in hematologic malignancies such as Burkitt lymphoma and acute lymphoblastic leukemia (ALL), TLS is now observed in malignancies that had rarely been associated with TLS, including solid tumors [4-9]. This change in pattern is likely the result of several factors including the availability of effective cytotoxic therapies for a wider range of malignancies, as well as an insufficient use of prophylactic therapies to adequately prevent TLS [1]. Although healthcare providers have expressed concerns regarding the TLS risk related to newer chemo modalities, they are not consistently utilizing straightforward measures for reducing TLS risk in their extended spectrum of patients at risk for TLS $[2,10,11]$. With

\footnotetext{
* Correspondence: alimcbride@gmail.com

1 Arthur G. James Cancer Hospital, The Ohio State University, Department of Pharmacy, Room 368 Doan Hall, Columbus, OH 43210, USA

Full list of author information is available at the end of the article
}

increasingly powerful chemotherapy agents being used to treat patients, it is more important than ever that patients undergo risk assessment for TLS in order that they may receive appropriate treatment to reduce the risk of occurrence. In the present article, we explore several key areas relevant to the evolving knowledge of TLS prevention that reflect the changing nature of the disease in the current clinical setting, and some frequently overlooked issues important to an understanding of TLS. In addition, we review the current and changing approaches to risk assessment and management of TLS.

\section{Definition of TLS}

TLS occurs when the cellular components of tumor cells are released into the blood after lysis, typically after chemotherapy or radiation therapy [10]. It is characterized by hyperuricemia, hyperkalemia, hyperphosphatemia, and hypocalcemia, factors which may overtax the body's homeostatic mechanisms and overwhelm the capacity for normal excretion of these materials $[10,12]$. This, in turn, causes various manifestations of TLS, including acute renal failure $[10,12]$ and cardiac arrest

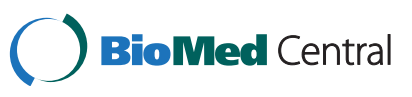


due to electrolyte abnormalities [10]. Malignancies, which typically result in TLS, are ones that possess a high proliferation rate and/or a large tumor burden, such as lymphomas and acute leukemias $[10,13]$. Moreover, patients whose melanoma is particularly sensitive to chemotherapy are also more likely to experience TLS [13]. Spontaneous TLS - that is, TLS occurring in the absence of cytotoxic therapy - is another concern among patients with malignancies who are at risk for TLS, and many of the same risk factors and preventive measures appropriate for TLS also apply to spontaneous TLS [6].

The standard definition for TLS comprises two separate definitions - clinical TLS (CTLS) and laboratory TLS (LTLS) - standardized by Cairo \& Bishop in 2004, and based on an earlier definition by Hande \& Garrow in 1993 [14,15] (Table 1). In 2011, Howard et al. suggested revisions to the Cairo \& Bishop definitions [1]. The modified Howard definition of LTLS is $\geq 2$ of the following metabolic abnormalities occurring simultaneously within 3 days prior to and up to 7 days after treatment initiation: hyperuricemia $(>8.0 \mathrm{mg} / \mathrm{dl})$, hyperkalemia ( $>6.0 \mathrm{mmol} /$ liter), hyperphosphatemia $(>4.5 \mathrm{mg} /$ $\mathrm{dl}$ ), and hypocalcemia (corrected $\mathrm{Ca}<7.0 \mathrm{mg} / \mathrm{dl}$, ionized $\mathrm{Ca}<1.12 \mathrm{mg} / \mathrm{dl}$ ). The modified Howard definition for CTLS is the same as laboratory-defined TLS, and is accompanied by elevated creatinine level, seizures, cardiac dysrhythmia, or death. In addition, any symptomatic hypocalcemia is considered diagnostic [1].

\section{TLS in solid tumors}

Although TLS has long been assumed to manifest primarily in hematologic malignancies, case reports of TLS in solid tumors have become increasingly common over the last decade [4-9]. The diversity of these reports is too broad to report comprehensively; however, below are several examples of the occurrence of TLS in varying types of solid tumors.

A 2006 publication by Mott et al. reported LTLS in three different patients-two with breast cancer and one with small cell carcinoma [16]. A 47-year old woman with metastatic breast cancer previously treated with doxorubicin and docetaxel developed TLS with diagnosis based on increased uric acid (UA) and lactate dehydrogenase (LDH), after initiating treatment with fluorouracil (5FU), epirubicin and cyclophosphamide (FEC). Her

Table 1 Comparison of tumor lysis syndrome (TLS) definitions

\begin{tabular}{|c|c|c|c|}
\hline Reference & Laboratory TLS & Clinical TLS & Other \\
\hline \multirow{6}{*}{$\begin{array}{l}\text { Hande \& } \\
\text { Garrow } 1993 \\
{[15]}\end{array}$} & $\begin{array}{l}\geq 2 \text { of the following metabolic abnormalities occurring within } \\
4 \text { days of treatment: }\end{array}$ & $\begin{array}{l}\text { Laboratory-defined TLS accompanied } \\
\text { by any of the following: }\end{array}$ & \multirow[t]{6}{*}{-} \\
\hline & O $25 \%$ increase from baseline in UA & O Creatinine level $>221 \mu \mathrm{mol} / \mathrm{l}(2.5 \mathrm{mg} / \mathrm{dL})$ & \\
\hline & O 25\% increase from baseline in potassium & O Potassium level $>6$ mmol/L (6 mEq/L) & \\
\hline & O 25\% increase from baseline in phosphate & O Calcium <1.5 mmol/L (6 mg/dL) & \\
\hline & \multirow[t]{2}{*}{ O 25\% decline from baseline in calcium } & O Development of a life-threatening arrhythmia & \\
\hline & & O Sudden death & \\
\hline \multirow[t]{5}{*}{$\begin{array}{l}\text { Cairo \& } \\
\text { Bishop } 2004 \\
\text { [13] }\end{array}$} & $\begin{array}{l}\geq 2 \text { of the following metabolic abnormalities occurring } \\
\text { simultaneously within } 3 \text { days prior to and up to } 7 \text { days } \\
\text { post-treatment initiation: }\end{array}$ & $\begin{array}{l}\text { Laboratory-defined TLS accompanied by } \\
\text { any of the following: }\end{array}$ & \multirow[t]{5}{*}{-} \\
\hline & $\circ \cup A \geq 476 \mu \mathrm{mol} / \mathrm{L}$ or $25 \%$ increase from baseline & $\begin{array}{l}\text { Elevated creatinine level ( } \geq 1.5 \text { ULN for } \\
\text { patients }>12 \text { years of age or age-adjusted) }\end{array}$ & \\
\hline & O Potassium $\geq 6.0 \mathrm{mmol} / \mathrm{L}$ or $25 \%$ increase from baseline & O Seizures & \\
\hline & $\begin{array}{l}\text { O Phosphorous } \geq 2.1 \mathrm{mmol} / \mathrm{L} \text { (children) } \geq 1.45 \mathrm{mmol} / \mathrm{L} \text { (adults) } \\
\text { or } 25 \% \text { increase from baseline }\end{array}$ & O Cardiac dysrhythmia & \\
\hline & O Calcium $\leq 1.75 \mathrm{mmol} / \mathrm{L}$ or $25 \%$ decrease from baseline & O Death & \\
\hline \multirow[t]{7}{*}{$\begin{array}{l}\text { Howard SC, } \\
\text { et al. } 2011 \\
{[1]}\end{array}$} & $\begin{array}{l}\geq 2 \text { of the following metabolic abnormalities occurring } \\
\text { simultaneously within } 3 \text { days prior to and up to } \\
7 \text { post-treatment initiation: }\end{array}$ & $\begin{array}{l}\text { Laboratory-defined TLS accompanied by } \\
\text { any of the following: }\end{array}$ & \multirow[t]{7}{*}{$\begin{array}{l}\text { Any symptomatic } \\
\text { hypocalcemia is } \\
\text { diagnostic }\end{array}$} \\
\hline & \multirow{2}{*}{$\begin{array}{l}\text { O UA }>8.0 \mathrm{mg} / \mathrm{dL}(475.8 \mu \mathrm{mol} / \mathrm{L}) \text { or above ULN for age } \\
\text { in children }\end{array}$} & O Elevated creatinine & \\
\hline & & O level & \\
\hline & O Potassium $>6.0 \mathrm{mmol} / \mathrm{L}$ & O Seizures & \\
\hline & \multirow{2}{*}{$\begin{array}{l}\text { O Phosphorus }>4.5 \mathrm{mg} / \mathrm{dL}(1.5 \mathrm{mmol} / \mathrm{L}) \text { or }>6.5 \mathrm{mg} / \mathrm{dL} \\
(2.1 \mathrm{mmol} / \mathrm{L}) \text { in children }\end{array}$} & \multirow{3}{*}{$\begin{array}{l}\text { O Cardiac dysrhythmia } \\
\text { O Death }\end{array}$} & \\
\hline & & & \\
\hline & 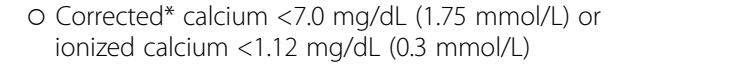 & & \\
\hline
\end{tabular}


LDH and UA - though unrecorded prior to chemotherapy-reached $916 \mathrm{IU} / \mathrm{dL}$ (normal range 60-200) and 10 $\mathrm{mg} / \mathrm{dL}$ (normal range 2.4-7.9), respectively, after one day of treatment. These levels decreased to some extent by the evening of day 2 , and although the UA level normalized, LDH remained well above the normal range [16]. In the second case, a 44-year old woman with breast cancer initially treated with docetaxel without complication developed TLS, after gemcitabine plus cisplatin was initiated for metastatic disease. The patient's laboratory values were significant for elevated LDH, phosphorus, potassium, UA, creatinine, and decreased calcium after 4 days of carboplatin and etoposide. Also reported was a 76-year-old woman with small cell carcinoma who developed elevated UA, serum potassium, phosphorus, and decreased calcium after 4 days of carboplatin and etoposide [16].

TLS in non-small cell lung cancer (NSCLC) - both squamous cell carcinoma and adenocarcinoma - has been reported in several instances, including after treatment with docetaxel, zoledronic acid, radiotherapy, and in at least one case, arising spontaneously [6-9]. A patient with metastatic colon cancer, for whom chemotherapy had been ruled out due to liver metastases causing hyperbilirubinemia and transaminitis, underwent treatment with the monoclonal antibody cetuximab [17]. Renal function deteriorated after 18 hours, and the patient experienced elevations in UA, phosphorus, potassium, and decreased calcium, consistent with CTLS.

Intense tumor lysis (though not diagnostic for TLS) was seen in a 33-year-old patient with hepatocellular carcinoma who was treated with sorafenib, a tyrosine kinase inhibitor [4]. Four days after treatment initiation, he experienced fatigue and fever; laboratory studies found that compared with pre-treatment baseline, his potassium had increased and calcium decreased, although creatinine and phosphorus were roughly unchanged and his UA had decreased [4].

A 44-year-old patient with primary retroperitoneal soft-tissue sarcoma was given a combination chemotherapy regimen of cisplatin, adriamycin, and dacarbazine after a chemosensitivity assay revealed that the malignancy was sensitive to these agents [5]. After 4 days, the patient experienced palpitations, dyspnea, chest tightness, and oliguria, accompanied by abnormally high creatinine as well as hyperuricemia, hyperphosphatemia, hypocalcemia diagnostic for CTLS, and acute renal failure. CTLS was also reported in a 60-year-old patient with recurrent endometrial cancer who had been receiving carboplatin and paclitaxel [18]. Four days after receiving treatment with both agents, she presented to the emergency room with dyspnea, weakness, fatigue, metabolic and electrolyte abnormalities, as well as UA, potassium, and phosphate levels consistent with TLS [18].
Case reports of TLS resulting from the treatment of metastatic melanoma (MM) have also been published. A 56-year-old patient with abdominal pain, vomiting, and weight loss, ongoing for 2 months, was diagnosed with MM and treated with intravenous hydrocortisone for hypercalcemia [19]. By the following day, lab values indicated the onset of CTLS; treatment for TLS along with discontinuation of the hydrocortisone resulted in a resolution of symptoms [19]. A 61-year-old patient presented with a nevus in the abdominal wall, and melanoma extending to lateral margin and invading the lymphatic channels was diagnosed and excision performed [20]. Six months later, melanoma was found in 6 of 15 lymph nodes, the MM having expanded despite treatment with one cycle of granulocyte macrophage-colony stimulating factor. Chemotherapy of cisplatin, vinblastine, and dacarbazine was initiated, along with interleukin- 2 and interferon- $\alpha$. LDH rose dramatically within 24 hours. By day 3 , CTLS symptoms had emerged and the following day chemotherapy was discontinued.

A 41-year-old patient with metastatic melanoma initiated on cisplatin, dacarbazine and interferon developed oliguria on day 2 after chemotherapy and symptoms of CTLS by day 4; acute renal failure developed shortly thereafter [21]. The potential greater potency of new chemotherapeutic regimens may be associated with a heightened risk for TLS.

\section{Spontaneous TLS}

The term "spontaneous TLS" refers to manifestations of TLS in patients who have not received cytotoxic therapy [6]. As with treatment-related TLS, spontaneous TLS was thought to be primarily confined to hematologic cancers [6]. While this is largely the case, incidences of spontaneous TLS in solid tumors have been reported $[11,13]$. Case reports of spontaneous TLS in hematologic cancers include cases occurring in patients with Burkitt lymphoma, non-Hodgkin's lymphoma, acute myeloid leukemia, B-cell lymphoma, and ALL, among others [11,22-27]. Solid tumors in which spontaneous TLS has been observed include breast cancer, gastric cancer, germ cell tumors, gastrointestinal adenocarcinoma, squamous cell lung carcinoma, and metastatic castrateresistant prostate cancer [6,28-32]. Hyperphosphatemia is less common in spontaneous than nonspontaneous TLS, possibly because phosphate release in lysis is less achievable when cytotoxic therapy has taken place [33].

\section{TLS risk factors}

Risk assessment is fundamental to the management of TLS, particularly in light of the highly effective prevention and treatment options available to clinicians. While general risk factors for TLS are typically well understood, stratifying patients with specific malignancy types, 
at specific disease stages, with particular disease manifestations is a considerably more complex task [13]. Cairo et al. developed several risk assessment models that allow for risk estimation based on cancer type as well as several key factors, including choice of chemotherapy, state of renal function, and disease stage, among other considerations [34]. These models, while informative, may be challenging to implement in the clinical setting, in part because they comprise 6 separate algorithms. Howard et al. developed a single simplified algorithm for risk assessment together with recommended therapy which, while less detailed, is somewhat more accessible for clinical purposes [1] (Figure 1). An adaptation of an algorithm developed by Wetzstein, for an overall approach to the management of TLS, is seen in Figure 2.

Risk factors for TLS related to tumor size and expansion include bulky tumor, wide metastatic dispersal, and organ and/or bone marrow involvement $[1,13]$. TLS risk is increased when a high potential for cell lysis exists; for example, in cases of high proliferation and tumor sensitivity to particular cytotoxic therapies, and during times when therapy intensity is particularly high [35]. Patients' health status, beyond malignancy-related factors, can also influence the risk of TLS, including presence of hypotension, dehydration, acidic urine (because of the greater propensity of UA to crystalize at low $\mathrm{pH}$ ), oliguria, pre-cancer nephropathy, and previous experience with nephrotoxic agents $[1,36]$. Medications and other compounds that tend to increase UA levels (Table 2) are additional risk factors for TLS.

\section{Considerations in the management of TLS}

Several key considerations and specific tasks are fundamental in the management of TLS. These include risk assessment, fluid management for TLS prophylaxis, and appropriate drug therapy for prophylaxis and TLS treatment. In addition, where rasburicase therapy will be applied, ongoing debates and current knowledge regarding appropriate dosage amounts and approaches to dosing (eg, flat dosing versus weight-based dosing) must be taken into consideration.

Clinical experience suggests that provision of appropriate prophylactic therapy for TLS may be the difference between successful and unsuccessful outcomes in at-risk patients [1]. Appropriate management of TLS should be centered around risk assessment of cancer patients, preventive treatment where appropriate, electrolyte monitoring in patients undergoing cytotoxic therapy, and rapid appropriate therapeutic intervention as necessary [10].

Fluid management is key in the prevention of TLS [13]. This involves both the vigorous application of hydration and diuresis to maintain a flow of urine that will dispose of systemic UA and phosphate. Urine alkalinization with sodium bicarbonate had been a standard approach in TLS management to increase urate excretion [14]. Alkalinization is, however, associated with a reduction in the solubility of calcium phosphate, thus potentially creating the problem in the setting of hyperphosphatemia, a more serious condition than the one it aims to treat $[1,13]$. The 2008 guidelines for the management of TLS state that sodium bicarbonate is no longer recommended for TLS management [13]. The rationale for this recommendation is that although alkalinization promotes UA excretion, it has a relatively small impact on xanthine and hypoxanthine solubility. Allopurinol, a cornerstone of TLS prevention, is used to prevent formation of UA. It decreases the formation of UA by inhibition the enzyme (XO) that converts xanthine to hypoxanthine to UA. Inhibition of $\mathrm{XO}$ leads to increased levels of xanthine and hypoxanthine. Therefore, due to the risk of both xanthine crystallization, calcium phosphate precipitation, as well as the occurrence of metabolic alkalosis associated with alkalization, the utility of routine use of sodium bicarbonate for the prevention of TLS has fallen out of favor [13]. Taken together, this risk plus the risk of calcium phosphate precipitation, as well as that of the metabolic alkalosis associated with alkalinization, challenges the clinical utility of sodium bicarbonate. It is also the case that in patients being treated with rasburicase, alkalinization has been associated with the potential risk of acute renal failure, and the 2008 TLS guidelines regard alkalinization as contraindicated in patients treated with rasburicase [13,39].

Allopurinol is commonly used in TLS management to reduce the conversion of xanthine and hypoxanthine to UA, a process for which it is highly effective [13]. Allopurinol is, however, ineffective at reducing UA formed prior to treatment, and its slow time to efficacy can necessitate delaying chemotherapy or reducing the dose of chemotherapy for patients in acute renal failure. Due to its low levels of solubility, allopurinol, by increasing systemic levels of xanthine and hypoxanthine, can also promote obstructive uropathy [40]. Reduced clearance of purine-based chemotherapeutic drugs is an additional feature of allopurinol that may require the dose reduction of these chemotherapeutic agents $[1,13]$.

Rasburicase, the first recombinant uricolytic agent, rapidly reduces UA levels by eliminating existing UA $[1,41]$. The efficacy of rasburicase in depleting UA involves its enzymatic degradation of UA into allantoin, which is highly soluble and is not associated with adverse effects in human patients [1]. Investigators have demonstrated rasburicase to be safe and effective for prophylaxis or treatment of hyperuricemia in patients with leukemia or lymphoma [41,42]. Rasburicase is FDA approved for initial management of pediatric and adult patients with leukemia, lymphoma, and solid tumor malignancies who are receiving anticancer therapy expected to result in 


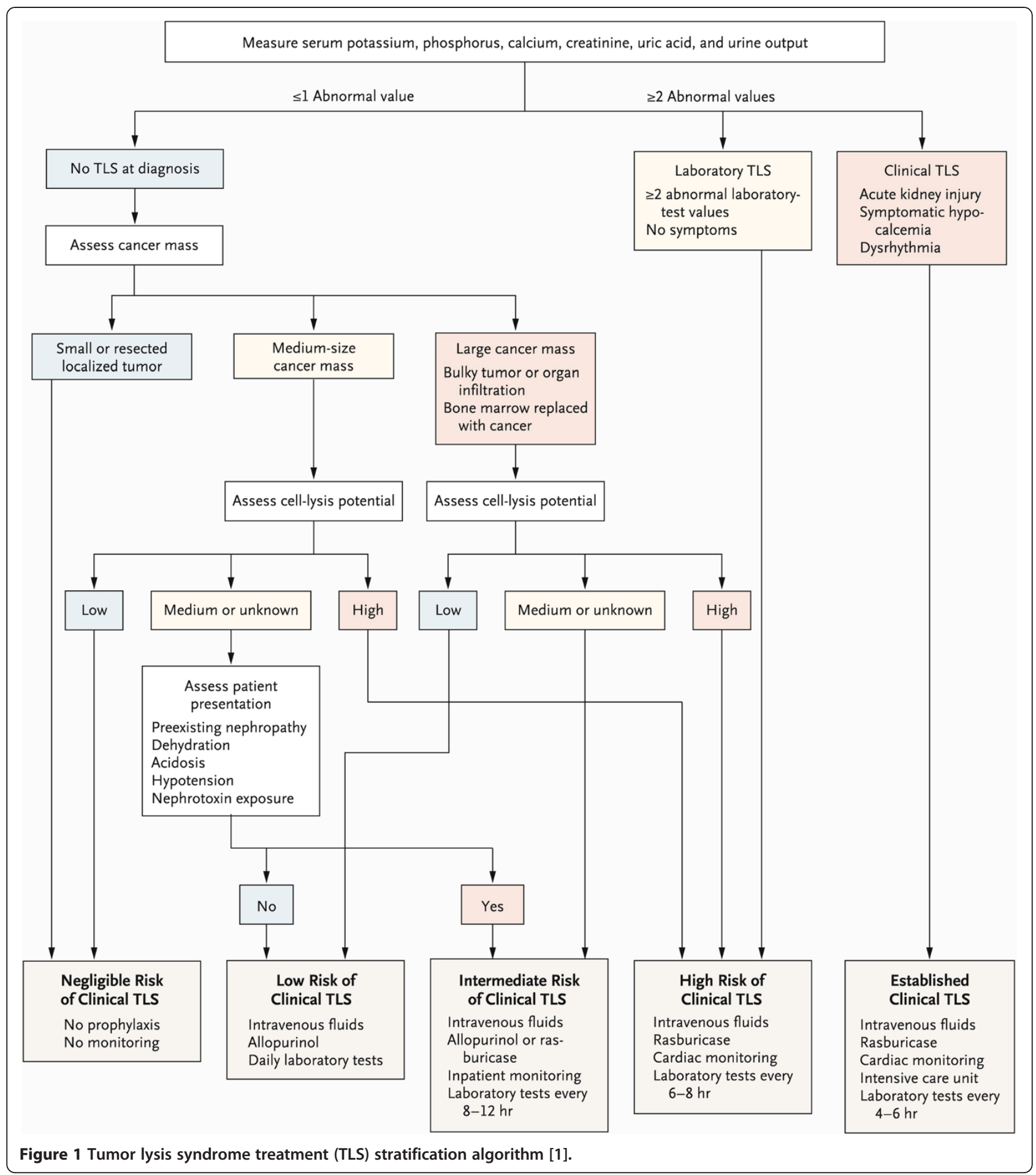

tumor lysis and subsequent elevation of plasma UA [43]. Rasburicase is recommended as a first-line therapy for patients at high risk of TLS, and is also used in Europe to treat intermediate-risk adult patients [13].

It should be noted that rasburicase is contraindicated in patients with a glucose-6-phosphate dehydrogenase (G6PD) deficiency as these patients are at an elevated risk for hemolysis [43]. Patients who are more likely to have a G6PD deficiency include African Americans and some people of Mediterranean and Southeast Asian descent [13].

The potential benefits of using rasburicase in sequential combination with allopurinol was explored in an open-label phase III study in which 275 patients with 


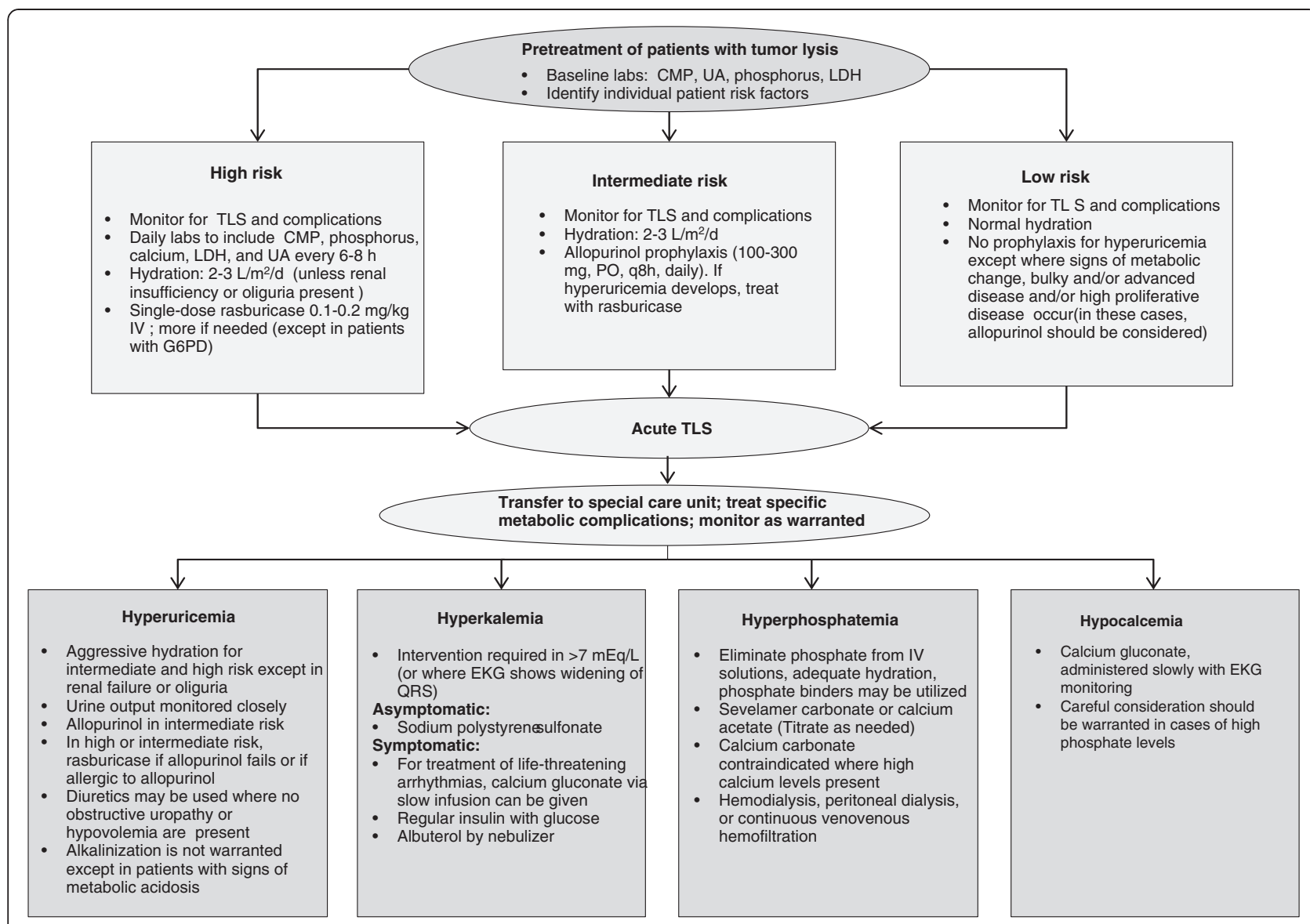

Figure 2 Algorithm for the management of tumor lysis syndrome (TLS) [3,13,34]. CMP, complete metabolic panel, EKG, electrocardiogram; G6PD, glucose-6-phosphate dehydrogenase; IV, intravenous; LDH, lactic dehydrogenase; PO, by mouth.

hematologic malignancies were randomized to receive allopurinol $(300 \mathrm{mg} / \mathrm{d})$ or rasburicase $(0.20 \mathrm{mg} / \mathrm{kg} / \mathrm{d})$ or both over a period of 5 days [2]. The sequential combination group received rasburicase on days 1 through 3 and allopurinol on days 3 through 5 with an overlap on day 3. The response rates with regard to serum UA were $87 \%$ for those treated only with rasburicase, $78 \%$ for those treated with the combination, and $66 \%$ for allopurinol monotherapy [2]. Rasburicase was significantly more effective than allopurinol $(P=0.001)$, while the combination did not reach statistically significant superiority over allopurinol alone $(P=0.06)$. Similar results

Table 2 Compounds associated with increasing uric acid in the body $[37,38]$

\begin{tabular}{lll}
\hline Alcohol & Diazoxide & Methyldopa \\
\hline Ascorbic acid & Diuretics (Thiazide) & Nicotinic acid \\
\hline Aspirin & Epinephrine & Pyrazinamide \\
\hline Caffeine & Ethambutol & Phenothiazines \\
\hline Cisplatin & Levodopa & Theophylline \\
\hline
\end{tabular}

were observed in subgroups of patients at elevated risk for TLS and for those with hyperuricemia at baseline. Treatment-related AEs were rare and similar between treatment groups. Two subjects in each of the monotherapy groups experienced acute renal failure $(2 \%$ for each group), while 5 subjects (5\%) in the combination therapy group experienced acute renal failure [2].

\section{Dosing of rasburicase}

The ideal method of dosing rasburicase has been an area of some debate, with one-time dosing, either as a fixed or weight-based dose, being preferred by many over weightbased, multi-dose therapy. Indeed, despite the FDA's dosing recommendation of $0.2 \mathrm{mg} / \mathrm{kg} / \mathrm{d}$ for up to 5 days, most rasburicase prophylactic treatment in the United States employs a flat dose of $3 \mathrm{mg}$ to $7.5 \mathrm{mg}$ daily [43]. A series of small studies have demonstrated the efficacy of a single fixed or weight-based dose of rasburicase in reducing UA in TLS patients or patients at high risk for TLS. Fixed-doses employed in these studies were $3 \mathrm{mg}, 6$ $\mathrm{mg}$, and $7.5 \mathrm{mg}$. Weight-based dosing was either 0.15 or 
Table 3 Pharmacologic therapies for the treatment of tumor lysis syndrome (TLS) [3]

\begin{tabular}{|c|c|c|}
\hline & Medication & Mechanism of Action \\
\hline Hyperuricemia & Allopurinol & $\begin{array}{l}\text { Potent inhibitor of xanthine } \\
\text { oxidase, the enzyme responsible } \\
\text { for the conversion of } \\
\text { hypoxanthine to xanthine to } \\
\text { uric acid. }\end{array}$ \\
\hline
\end{tabular}

Dosage/Administration

PO: $200-300 \mathrm{mg} / \mathrm{m}^{2} \mathrm{gd}$

administration of $>300 \mathrm{mg}$

should be given in divided

doses ( $\max , 800 \mathrm{mg} / \mathrm{d}$ ); should initiate therapy 24 to 48 hours prior to chemotherapy.

Adult (IV): $200-400 \mathrm{mg} / \mathrm{m}^{2} / \mathrm{d}$ as a single infusion or divided doses (max, $600 \mathrm{mg} / \mathrm{d}$ ); infuse over 1560 minutes; final concentration no

Pediatric (IV): Starting dose $200 \mathrm{mg} / \mathrm{m}^{2} / \mathrm{d}$. greater than $6 \mathrm{mg} / \mathrm{mL}$.

\section{Rasburicase}

Recombinant protein that catalyzes enzymatic oxidation of uric acid into an inactive metabolite, allantoin, that is 5 to 10 times more soluble than uric acid.
Adult: $0.2 \mathrm{mg} / \mathrm{kg}$ infusion over 30 minutes once daily for up to 5 days*; no dosing adjustment required in renal or hepatic dysfunction.

Pediatric: $0.15-0.2 \mathrm{mg} / \mathrm{kg} \mathrm{IV}$ infusion over 30 minutes daily $x$ 5 days*; no dosing adjustment required in renal or hepatic dysfunction.

*Studies using single dose in the treatment of hyperuricemia has been reported [55].

\section{Comments}

Adverse events include maculopapular rash, dyspepsia nausea/ vomiting, fever, and eosinophilia; rare reports of interstitial nephritis; decreases in serum uric acid occur in 1 to 2 days with a nadir $~ 7$ days; dosage adjustment in renal dysfunction is necessary to avoid accumulation of the active metabolite oxypurinol (alloxanthine); removed by dialysis, so administer posthemodialysis or administer 50\% supplemental dose; significant drug interactions with azathioprine and

6-mercaptopurine; the dose of concomitant azathioprine or 6-mercaptopurine should be reduced to one third to one fourth of their usual dose.

Adverse events include nausea/ vomiting, fever, headache, abdominal pain, constipation, diarrhea, and rash. Rare $(<1 \%)$ but serious reactions have occurred such as severe hypersensitivity reactions, including anaphylaxis, hemolysis, and methemoglobinemia. Caution is advised in patients who have atopic allergies/asthma.

Contraindicated in individuals deficient in glucose-6phosphatase dehydrogenase (G6PD). Rasburicase will cause enzymatic degradation of uric acid within blood samples left at room temperature, resulting in spuriously low uric acid levelsblood must be collected into prechilled tubes containing heparin anticoagulant and immediately immersed and maintained in an ice water bath; plasma samples must be assayed within 4 hours of sample collection.

\begin{tabular}{llll}
\hline Hyperkalemia & $\begin{array}{l}\text { Sodium } \\
\text { polystyrene } \\
\text { sulfonate }\end{array}$ & $\begin{array}{l}\text { Removes potassium }(\mathrm{K}+) \text { by } \\
\text { exchanging sodium ions }(\mathrm{Na}+) \\
\text { for } \mathrm{K}+\text { in the intestine. }\end{array}$ & $\begin{array}{l}\text { Adult: } 15 \mathrm{~g} \mathrm{PO}(60 \mathrm{~mL}) 1 \text { to } \\
4 \text { times per day }\end{array}$ \\
& & $\begin{array}{l}\text { Pediatric: } 1 \mathrm{~g} / \mathrm{kg} / \mathrm{dose} \text { PO q6h } \\
\text { or q2-6h rectally. }\end{array}$
\end{tabular}

$1 \mathrm{~g}$ resin binds approximately $1 \mathrm{mEq}$ of $\mathrm{K}+$; onset is variable $\sim 2$ to 24 hours; administer orally or nasogastrically with a laxative such as sorbitol to avoid fecal impaction and facilitate elimination; chilling the solution will increase palatability; enema route is usually less effective.

\begin{tabular}{lll}
\hline Calcium & Raises threshold potential and & Adult: $1-3 \mathrm{~g}$ over 3 to 5 minutes \\
gluconate & reestablishes cardiac excitability. & IV push.
\end{tabular}

Antagonizes the action of hyperkalemia on the heart; should be monitored closely by ECG when given; onset $~ 1$ Pediatric: $60-200 \mathrm{mg} / \mathrm{kg}$ over 3 to 5 minutes slow IV push. to 2 minutes; duration is $\sim 10$ to 30 minutes. 
Table 3 Pharmacologic therapies for the treatment of tumor lysis syndrome (TLS) [3] (Continued)

\begin{tabular}{|c|c|c|c|c|}
\hline & \multirow[t]{2}{*}{ Loop diuretics } & \multirow[t]{2}{*}{$\begin{array}{l}\text { Inhibits reabsorption of } \mathrm{Na}+ \\
\text { and chloride, thus causing } \\
\text { increased excretion of fluid, } \\
\mathrm{K}+\text {, and phosphate. }\end{array}$} & $\begin{array}{l}\text { Adult: bumetanide: } 0.5-1 \mathrm{mg} \mathrm{IV} \\
\text { or PO } 1 \text { to } 2 \text { times per day ( } 1 \mathrm{mg}= \\
40 \mathrm{mg} \text { furosemide); ethacrynic } \\
\text { acid (PO) or ethacrynate } \\
\text { sodium (IV [Edecrin, Merck]): } 0.5- \\
1 \mathrm{mg} / \mathrm{kg} / \mathrm{dose} \text { IV or PO q8-12h } \\
\mathrm{prn} \text {; furosemide: } 20-80 \mathrm{mg} / \mathrm{dose} \\
\text { IV or PO q6-12h prn; torsemide: } \\
10-20 \mathrm{mg} \text { IV or PO every day prn } \\
\text { (20-30 mg = } 40 \mathrm{mg} \text { furosemide). }\end{array}$ & \multirow[t]{2}{*}{$\begin{array}{l}\text { Onset: IV 5 minutes; PO } \\
\sim 30 \text { to } 60 \text { minutes; duration } \\
\sim 6 \text { to } 12 \text { hours, depending on } \\
\text { agent; monitor for blood } \\
\text { pressure, electrolytes, and } \\
\text { renal function. }\end{array}$} \\
\hline & & & $\begin{array}{l}\text { Pediatric: bumetanide } \\
\text { (>6 months): } 0.015-0.1 \mathrm{mg} / \mathrm{kg} / \mathrm{dose} \\
\text { once or twice daily (safety and } \\
\text { efficacy have not been } \\
\text { established in children }<18 \text { ); } \\
\text { ethacrynic acid: } 25 \mathrm{mg} \text { PO daily } \\
\text { (maximum dose, } 2-3 \mathrm{mg} / \mathrm{kg} / \mathrm{d} \text { ); } \\
\text { furosemide } 1-2 \mathrm{mg} / \mathrm{kg} / \mathrm{dose} \text { IV } \\
\text { or PO q6-8h prn (maximum daily } \\
\text { dose, } 40 \mathrm{mg} \text { ). }\end{array}$ & \\
\hline & \multirow[t]{2}{*}{$\begin{array}{l}\text { Dextrose and } \\
\text { regular insulin }\end{array}$} & \multirow[t]{2}{*}{ Shifts K+ intracellularly. } & $\begin{array}{l}\text { Adult: } \mathrm{D}_{5} \mathrm{~W} \text { at } 0.5-1 \mathrm{~mL} / \mathrm{kg} \text { and } \\
\text { regular insulin } 1 \text { unit for every } \\
4-5 \mathrm{~g} \text { of dextrose given. }\end{array}$ & \multirow{2}{*}{$\begin{array}{l}\text { Onset is usually within } 30 \text { to } \\
60 \text { minutes; effects are } \\
\text { temporary, usually lasting } 2 \\
\text { to } 6 \text { hours. }\end{array}$} \\
\hline & & & $\begin{array}{l}\text { Pediatric: The dosage of regular } \\
\text { insulin is } 1 \text { unit for every } 4-5 \mathrm{~g} \\
\text { of dextrose; usually dextrose } 25 \% \\
\text { or } 50 \%(0.5-1 \mathrm{~g} / \mathrm{kg}) \text { is used with } \\
\text { insulin; dextrose } 0.5-1 \mathrm{~g} / \mathrm{kg} \text { can } \\
\text { also be infused over } 15 \text { to } \\
30 \text { minutes followed by insulin } \\
0.1 \text { unit } / \mathrm{kg} \text {. }\end{array}$ & \\
\hline & \multirow[t]{2}{*}{$\begin{array}{l}\text { Sodium } \\
\text { bicarbonate }\end{array}$} & \multirow[t]{2}{*}{$\begin{array}{l}\text { Increases serum } \mathrm{pH} \text { and causes } \\
\text { a temporary shift of } \mathrm{K}+\text { into cells. }\end{array}$} & $\begin{array}{l}\text { Adult: } 50 \mathrm{mEq} \text { as IV bolus, or } 50- \\
150 \mathrm{mEq} \text { added to } 1 \text { liter } \mathrm{D}_{5} \mathrm{~W} \\
\text { and administered as an infusion. }\end{array}$ & \multirow{2}{*}{$\begin{array}{l}\text { Indicated for patients with } \\
\text { acidosis; onset } ~ 30 \text { to } \\
60 \text { minutes and may last } 2 \text { to } \\
6 \text { hours, but effects are } \\
\text { temporary (Sodium acetate } \\
\text { may be substituted for } \\
\text { Sodium bicarbonate when } \\
\text { in shortage). }\end{array}$} \\
\hline & & & $\begin{array}{l}\text { Pediatric: When sodium } \\
\text { bicarbonate is determined to be } \\
\text { necessary, an initial dose of } \\
1 \mathrm{mEq} / \mathrm{kg} \text { may be given initially } \\
\text { either IV or per intraosseous } \\
\text { route, followed by not more than } \\
\text { half of that dose every } \\
10 \text { minutes as needed. }\end{array}$ & \\
\hline \multirow[t]{3}{*}{ Hyperphosphatemia } & $\begin{array}{l}\text { Calcium acetate } \\
\text { (PhosLo, Nabi) }\end{array}$ & $\begin{array}{l}\text { Binds to phosphate taken in } \\
\text { through diet to form insoluble } \\
\text { calcium phosphate, which is } \\
\text { then excreted from the body } \\
\text { without being absorbed. }\end{array}$ & $\begin{array}{l}\text { Adult: } 2 \text { tablets or gelcaps } \\
\text { ( } 667 \mathrm{mg} \text { ) with each meal; dosage } \\
\text { may be increased gradually to bring } \\
\text { serum phosphate value } \\
<6 \mathrm{mg} / \mathrm{dL} \text { as long as hypercalcemia } \\
\text { does not develop. }\end{array}$ & $\begin{array}{l}\text { Adverse events include nausea, } \\
\text { mild hypercalcemia } \\
\text { (manifested as constipation, } \\
\text { anorexia, nausea and vomiting), } \\
\text { severe hypercalcemia } \\
\text { (associated with confusion, } \\
\text { delirium, stupor, coma), and } \\
\text { pruritus. Not recommended } \\
\text { unless patient is symptomatic } \\
\text { because of potential for } \\
\text { Ca/PO } \text { Precipitates to form, }_{\text {, }} \text { especially if alkalinizing } \\
\text { the urine. }\end{array}$ \\
\hline & \multirow[t]{2}{*}{$\begin{array}{l}\text { Sevelamer } \\
\text { (Renagel, } \\
\text { Genzyme) }\end{array}$} & \multirow{2}{*}{$\begin{array}{l}\text { Cross-linked poly(allylamine } \\
\text { hydrochloride) is a cationic } \\
\text { polymer that binds intestinal } \\
\text { phosphate. The compound } \\
\text { contains multiple amines that } \\
\text { are protonated in the intestinal } \\
\text { tract and interact with phosphate } \\
\text { via ion-exchange and hydrogen } \\
\text { bonding. }\end{array}$} & $\begin{array}{l}\text { Adult (PO): Recommended } \\
\text { starting dose is } 800-1,600 \mathrm{mg} \\
3 \text { times daily. }\end{array}$ & \multirow{2}{*}{$\begin{array}{l}\text { Adverse events include } \\
\text { nausea/vomiting, constipation, } \\
\text { diarrhea, flatulence, and } \\
\text { dyspnea. Sevelamer is a } \\
\text { calcium- and aluminum-free } \\
\text { phosphate binder so it may } \\
\text { be advantageous when } \\
\text { calcium-phosphate complexes } \\
\text { are of concern. }\end{array}$} \\
\hline & & & $\begin{array}{l}\text { Pediatric (PO): Clinical data are } \\
\text { lacking. }\end{array}$ & \\
\hline
\end{tabular}


Table 3 Pharmacologic therapies for the treatment of tumor lysis syndrome (TLS) [3] (Continued)

\begin{tabular}{|c|c|c|c|c|}
\hline \multirow[t]{2}{*}{ Hypocalcemia } & \multirow[t]{2}{*}{$\begin{array}{l}\text { Calcium } \\
\text { supplementation }\end{array}$} & \multirow[t]{2}{*}{$\begin{array}{l}\text { Exogenous calcium }(\mathrm{Ca}++) \\
\text { replacement. }\end{array}$} & $\begin{array}{l}\text { Adult: } 500-2,000 \text { mg elemental } \\
\text { calcium PO in divided doses; } 2- \\
3 \mathrm{~g} \mathrm{Ca++} \text { gluconate IV over } 1 \\
\text { to } 2 \text { hours. }\end{array}$ & \multirow{2}{*}{$\begin{array}{l}\text { Reserved for patients who are } \\
\text { symptomatic; elemental } \\
\text { Ca++ content: carbonate } \\
(40 \%)>\text { chloride }(27 \%)>\text { acetate } \\
(25 \%)>\text { gluconate }(9 \%) ; \\
\text { IV Ca++ gluconate is less } \\
\text { irritating than other Ca++ salts. }\end{array}$} \\
\hline & & & $\begin{array}{l}\text { Pediatric: } 200-2,000 \mathrm{mg} \\
\text { elemental calcium PO in divided } \\
\text { doses; Ca++ gluconate } 100 \mathrm{mg} / \mathrm{kg} \\
\text { dose IV over } 1 \text { to } 2 \text { hours. }\end{array}$ & \\
\hline
\end{tabular}

ECG, electrocardiogram; IV, intravenous; $\mathrm{PO}$, by mouth, $\mathrm{mEq}$; milliequivalent.

$0.05 \mathrm{mg} / \mathrm{kg}$ [44-51]. A retrospective review from 2006 examined the efficacy of a fixed $3 \mathrm{mg}$ dose of rasburicase given to 43 patients with hematologic malignancies who were receiving chemotherapy or hematopoietic stem cell transplantation. All subjects in the study were hyperuricemic, with 15 patients having laboratory values suggestive of TLS and the remainder at elevated risk for TLS. Patients were given allopurinol "as required", to suppress UA formation. Most patients experienced a significant decline in UA within the first 24 hours, and 6 subjects required an additional dose of rasburicase: 2 received a $1.5 \mathrm{mg}$ second dose and 4 received a $3 \mathrm{mg}$ second dose. Within 48 hours, UA had normalized in all patients and none required a third dose [51].

A retrospective review from 2009 assessed the use of a weight-based approach to rasburicase therapy in 21 cancer patients, with dosing based on ideal body weight $(n=11)$; in cases where a patient was in excess of $30 \%$ of the IBW $(\mathrm{n}=10)$, an adjusted dose was given. The average initial dose administered was $0.15 \mathrm{mg} / \mathrm{kg} \pm 0.03$. All patients in the study had laboratory values reflecting TLS or high risk for TLS, and all patients received allopurinol. Within 6 hours of treatment, the mean reduction from baseline of UA was $65.3 \% \pm 17.3$, and within 24 hours UA levels had been reduced by $89.7 \% \pm 9.0 \%$. No data regarding additional doses was reported [47]. Fixed-dose efficacy has also been shown in a small number of patients with spontaneous TLS [45].

A recently published chart review from our institution of single fixed-dose and weight-based dosing of rasburicase in 373 evaluated patients with malignancies, but at varying levels of risk for TLS, sought to determine the efficacy of these approaches to dosing in a larger and more diverse patient population [52]. The primary endpoint of this chart review was normalization of UA at 24 hours; secondary endpoints were UA normalization at 48 and 72 hours [52]. Treatment across all groups was found to be highly effective, with only 6 study subjects failing to achieve normalized UA levels within 24 hours. There were no significant differences between dosing groups for any of the endpoints, although $3 \mathrm{mg}$ was found to have a weaker effect on UA reduction. That is, while the $3 \mathrm{mg}$ dose was equally effective at achieving treatment success (i.e., $<7.5 \mathrm{mg} / \mathrm{dL}$ within 24 hours), the mean UA level at 24 hours in the $3 \mathrm{mg}$ group was $3.69 \mathrm{mg} / \mathrm{dL}$ compared to $1.71 \mathrm{mg} / \mathrm{dL}, 1.42 \mathrm{mg} / \mathrm{dL}$, and $1.03 \mathrm{mg} / \mathrm{dL}$ in the $6 \mathrm{mg}$, $7.5 \mathrm{mg}$, and weight-based dosing groups, respectively [52]. No significant differences between low, intermediate, and high-risk patient groups were observed at 24 or 72 hours, while such a difference was observed at 48 hours in the low-risk group $(\mathrm{P}=0.017)$ [52].

A recent randomized, open-label clinical trial compared two rasburicase regimens in 80 patients at high risk for TLS (defined as presence of hyperuricemia or very aggressive lymphoma or leukemia) or potential risk (defined as aggressive lymphoma or leukemia plus LDH $\geq$ upper normal limit, or stage or stage $\geq 3$ disease, or stage 1 or 2 disease with $\geq 1$ lymph node/tumor $>5 \mathrm{~cm}$ ) [53]. The regimens were $0.15 \mathrm{mg} / \mathrm{kg}$ given as a single dose followed by as-needed dosing versus the same dose given daily for 5 days. All but 1 patient experienced normalized UA within 24 hours, and UA reached undetectable levels within 4 hours for $84 \%$ of the study subjects. UA levels were largely sustained in both groups with the notable exception of 5 patients in the high-risk, single-dose arm who required a second dose during the 5-day study period. Two of these patients required a second dose on day 3, 1 patient on day 4, and 1 patient on day 5 . All 5 of these patients had very aggressive lymphoma and/or bulky tumor, including 3 with diffuse large B-cell lymphoma, 1 with Burkitt lymphoma, and 1 with Burkitt-like disease. No patients required a third dose [53].

Experience with rasburicase has shown it to be largely well tolerated, with side effects of this agent tending to cluster around hypersensitivity/allergic reactions. These include rash/pruritus, methemoglobinemia, fever, neutropenia, hypoxia, and, rarely, anaphylactic shock. Anemia can also occur, and, as previously noted, patients with G6PD deficiency should not be treated with rasburicase [52-55]. In the one head-to-head open-label study in which treatment with a single dose of rasburicase was compared to five daily doses, the incidence of the most common side effects-generally mild to moderate in severity (eg, nausea, constipation, diarrhea, and vomiting)-was notably less in the single-dose treatment group [53]. 


\section{Conclusions}

The development of a wider range of cytotoxic therapies and the application of, in some cases, more intensive therapy for the treatment of a variety of cancer types has increased the risk of TLS and the spectrum of its manifestations. Whereas TLS has been widely regarded as associated with hematologic malignancies, an increasing number of reports show that TLS also occurs in solid tumors. In addition, spontaneous TLS is seen more frequently, albeit it represents a minority of TLS cases.

The impact of TLS, as an oncologic emergency, often extends beyond the immediate consequences of the condition itself. In many cases TLS can cause delay of necessary chemotherapy, force a reduction in chemotherapy dosing and alter the selection of cytotoxic agents due to treatment toxicities overlapping with damage induced by TLS. Kidney damage, heart failure, fluid retention, neuromuscular effects, as well as gastrointestinal effects, are examples of damage that can occur. As many practitioners in the clinical setting have yet to fully realize the consequences of TLS, often associated with more effective cancer treatments and newer regimens, the likelihood of cancer patients at risk for TLS is probably underestimated, resulting in unnecessary patient morbidity and mortality [54,55].

With the availability of highly effective treatments for the prevention and management of TLS, it is worth reiterating the importance of risk assessment in cancer patients. Clinical experience has definitively demonstrated that the provision of appropriate prophylactic therapy for TLS at the appropriate dose can be the difference between successful and unsuccessful outcomes in at-risk patients. Preventive and therapeutic interventions for TLS have been shown to be highly effective and relatively easy to implement. (See Table 3 for a synopsis of pharmacologic therapies for the treatment of TLS).

\section{Abbreviations}

AE: Adverse event; ALL: Acute lymphoblastic leukemia; CAD: Chronic actinic dermatitis; CMP: Complete metabolic panel; COPD: Chronic obstructive pulmonary disease; CRPC: Castrate-resistant prostate cancer;

ECG: Electrocardiogram; FEC: Fluorouracil/epirubicin/cyclophosphamide; G6PD: Glucose-6-phosphate dehydrogenase; IV: Intravenous; LDH: Lactate dehydrogenase; MM: Metastatic melanoma; NHL: Non-Hodgkin's lymphoma; NSCLC: Non-small cell lung cancer; TLS: Tumor lysis syndrome; UA: Uric acid; ULN: Upper limit of normal.

\section{Competing interests}

The authors declare that they have no competing interests.

\section{Authors' contributions}

$\mathrm{AM}$ and $\mathrm{PW}$ were responsible for the conception and design of the manuscript. AM participated in drafting the manuscript, and both AM and PW were responsible for the review and/or revision of the manuscript. Both authors read and approved the final submitted manuscript.

\section{Acknowledgements}

Medical editorial writing assistance was provided by Susan DePetris, PhD, of Phase Five Communications Inc., and funded by sanofi-aventis U.S. LLC. The authors retained full editorial control over the content of the manuscript and received no compensation from any party for their work.

\section{Author details}

'Arthur G. James Cancer Hospital, The Ohio State University, Department of Pharmacy, Room 368 Doan Hall, Columbus, OH 43210, USA. ²Department of Medicine, Oncology Division, Washington University, St. Louis, MO, USA

Received: 13 September 2012 Accepted: 30 November 2012 Published: 13 December 2012

\section{References}

1. Howard SC, Jones DP, Pui CH: The tumor lysis syndrome. N Engl J Med 2011, 364:1844-1854.

2. Cortes J, Moore JO, Maziarz RT, Wetzler M, Craig M, Matous J, et al: Control of plasma uric acid in adults at risk for tumor lysis syndrome: efficacy and safety of rasburicase alone and rasburicase followed by allopurinol compared with allopurinol alone-results of a multicenter phase III study. J Clin Oncol 2010, 28:4207-4213.

3. Wetzstein GA: Tumor lysis syndrome-a treatment guide. Oncology 2002, 5:31-4.

4. Joshita S, Yoshizawa K, Sano K, Kobayashi S, Sekiguchi T, Morita S, et al: A patient with advanced hepatocellular carcinoma treated with sorafenib tosylate showed massive tumor lysis with avoidance of tumor lysis syndrome. Intern Med 2010, 49:991-994.

5. Qian KQ, Ye H, Xiao YW, Bao YY, Qi CJ: Tumor lysis syndrome associated with chemotherapy in primary retroperitoneal soft tissue sarcoma by ex vivo ATP-based tumor chemo-sensitivity assay (ATP-TCA). Int I Gen Med 2009, 2:1-4.

6. Shenoy C: Acute spontaneous tumor lysis syndrome in a patient with squamous cell carcinoma of the lung. QJM 2009, 102:71-73.

7. Noh GY, Choe DH, Kim CH, Lee JC: Fatal tumor lysis syndrome during radiotherapy for non-small-cell lung cancer. J Clin Oncol 2008 26:6005-6006.

8. Ajzensztejn D, Hegde VS, Lee SM: Tumor lysis syndrome after treatment with docetaxel for non-small-cell lung cancer. J Clin Oncol 2006, 24:2389-2391

9. Kurt M, Onal IK, Elkiran T, Altun B, Altundag K, Gullu I: Acute tumor lysis syndrome triggered by zoledronic Acid in a patient with metastatic lung adenocarcinoma. Med Oncol 2005, 22:203-6.

10. Hochberg J, Cairo MS: Tumor lysis syndrome: current perspective. Haematologica 2008, 93:9-13.

11. Ahamed SM, Varma RS, Mathew T, Hamide A, Badhe BA: Spontaneous tumour lysis syndrome associated with non-Hodgkin's lymphoma-a case report. Indian J Pathol Microbiol 2006, 49:26-28.

12. Howard SC, Pui CH: Pitfalls in predicting tumor lysis syndrome. Leuk Lymphoma 2006, 47:782-785.

13. Coiffier B, Altman A, Pui CH, Younes A, Cairo MS: Guidelines for the management of pediatric and adult tumor lysis syndrome: an evidence-based review. J Clin Oncol 2008, 26:2767-2778.

14. Cairo MS, Bishop M: Tumour lysis syndrome: new therapeutic strategies and classification. Br J Haematol 2004, 127:3-11.

15. Hande KR, Garrow GC: Acute tumor lysis syndrome in patients with highgrade non-Hodgkin's lymphoma. Am J Med 1993, 94:133-139.

16. Mott FE, Esana A, Chakmakjian C, Herrington JD: Tumor lysis syndrome in solid tumors. Support Cancer Ther 2005, 2:188-191.

17. Krishnan G, D'Silva K, Al-Janadi A: Cetuximab-related tumor lysis syndrome in metastatic colon carcinoma. J Clin Oncol 2008, 26:2406-2408.

18. Godoy $H$, Kesterson JP, Lele S: Tumor lysis syndrome associated with carboplatin and paclitaxel in a woman with recurrent endometrial cancer. Int J Gynaecol Obstet 2010, 109:254.

19. Habib GS, Saliba WR: Tumor lysis syndrome after hydrocortisone treatment in metastatic melanoma: a case report and review of the literature. Am J Med Sci 2002, 323:155-157.

20. Castro MP, VanAuken J, Spencer-Cisek P, Legha S, Sponzo RW: Acute tumor lysis syndrome associated with concurrent biochemotherapy of metastatic melanoma: a case report and review of the literature. Cancer 1999, 85:1055-1059.

21. Stoves J, Richardson D, Patel H: Tumour lysis syndrome in a patient with metastatic melanoma treated with biochemotherapy. Nephrol Dial Transplant 2001, 16:188-189.

22. Verma A, Mathur R, Chauhan M, Ranjan P: Tumor lysis syndrome developing intraoperatively. J Anaesthesiol Clin Pharmacol 2011, 27:561-563. 
23. Opyrchal M, Figanbaum T, Ghosh A, Rajkumar V, Caples S: Spontaneous tumor lysis syndrome in the setting of B-cell lymphoma. Case Report Med 2010, 2010:610969. 1-3.

24. Riccio B, Mato A, Olson EM, Berns JS, Luger S: Spontaneous tumor lysis syndrome in acute myeloid leukemia: two cases and a review of the literature. Cancer Biol Ther 2006, 5:1614-1617.

25. Barquero Romero J, Catalina Fernández I, Hernández Sáez C, Jiménez Morales JL, García de la Llana F: Spontaneous tumor lysis syndrome in a patient with non-Hodgkin's lymphoma. An Med Interna 2005, 22:387-389.

26. Sharma SK, Malhotra P, Kumar M, Sharma A, Varma N, Singh S: Spontaneous tumor lysis syndrome in acute lymphoblastic leukemia. J Assoc Physicians India 2005, 53:828-830.

27. Jasek AM, Day HJ: Acute spontaneous tumor lysis syndrome. Am J Hematol 1994, 47:129-131.

28. Lin CJ, Hsieh RK, Lim KH, Chen HH, Cheng YC, Wu CJ: Fatal spontaneous tumor lysis syndrome in a patient with metastatic, androgenindependent prostate cancer. South Med J 2007, 100:916-917.

29. Pentheroudakis G, O'Neill VJ, Vasey P, Kaye SB: Spontaneous acute tumou lysis syndrome in patients with metastatic germ cell tumours. Report of two cases. Support Care Cancer 2001, 9:554-557.

30. Woo IS, Kim JS, Park MJ, Lee MS, Cheon RW, Chang HM, et al: Spontaneous acute tumor lysis syndrome with advanced gastric cancer. J Korean Med Sci 2001, 16:115-118.

31. Sklarin NT, Markham M: Spontaneous recurrent tumor lysis syndrome in breast cancer. Am J Clin Oncol 1995, 18:71-73.

32. Crittenden DR, Ackerman GL: Hyperuricemic acute renal failure in disseminated carcinoma. Arch Intern Med 1977, 137:97-99.

33. Kjellstrand CM, Cambell DC II, von Hartitzsch B, Buselmeier TJ: Hyperuricemic acute renal failure. Arch Intern Med 1974, 133:349-359.

34. Cairo MS, Coiffier B, Reiter A, Younes A, TLS Expert Panel: Recommendations for the evaluation of risk and prophylaxis of tumour lysis syndrome (TLS) in adults and children with malignant diseases: an expert TLS panel consensus. Br J Haematol 2010, 149:578-586.

35. Kennedy LD, Koontz S, Rao K: Emerging role of rasburicase in the management of increased plasma uric acid levels in patients with hematologic malignancies. J Blood Med 2011, 2:1-6.

36. Michallet AS, Tartas S, Coiffier B: Optimizing management of tumor lysis syndrome in adults with hematologic malignancies. Support Cancer Ther 2005, 2:159-166.

37. Doherty M: New insights into the epidemiology of gout. Rheumatology (Oxford) 2009, 48(Suppl 2):ii2-ii8.

38. National Library of Medicine: MedlinePlus: Uric acid - blood http://www.n/m.nih.gov/medlineplus/ency/article/003476.htm.

39. van den Berg $H$, Reintsema AM: Renal tubular damage in rasburicase: risks of alkalinisation. Ann Oncol 2004, 15:175-176.

40. Ablin A, Stephens BG, Hirata T, Wilson K, Williams HE: Nephropathy, xanthinuria, and orotic aciduria complicating Burkitt's lymphoma treated with chemotherapy and allopurinol. Metabolism 1972, 21:771-778.

41. Pui CH, Mahmoud HH, Wiley JM, Woods GM, Leverger G, Camitta B, et al Recombinant urate oxidase for the prophylaxis or treatment of hyperuricemia in patients with leukemia or lymphoma. J Clin Oncol 2001, 19:697-704.

42. Goldman SC, Holcenberg JS, Finklestein JZ, Hutchinson R, Kreissman S, Johnson $\mathrm{FL}$, et al: A randomized comparison between rasburicase and allopurinol in children with lymphoma or leukemia at high risk for tumor lysis. Blood 2001, 97:2998-3003.

43. Elitek [package insert]. Bridgewater, NJ: sanofi-aventis U.S, LLC; 2011.

44. Knoebel RW, Lo M, Crank CW: Evaluation of a low, weight-based dose of rasburicase in adult patients for the treatment or prophylaxis of tumor lysis syndrome. J Oncol Pharm Pract 2011, 17:147-154.

45. Giraldez $M$, Puto K: A single, fixed dose of rasburicase (6 mg maximum) for treatment of tumor lysis syndrome in adults. Eur J Haematol 2010, 85:177-179.

46. Vines AN, Shanholtz CB, Thompson JL: Fixed-dose rasburicase $6 \mathrm{mg}$ for hyperuricemia and tumor lysis syndrome in high-risk cancer patients. Ann Pharmacother 2010, 44:1529-1537.

47. Campara M, Shord SS, Haaf CM: Single-dose rasburicase for tumour lysis syndrome in adults: weight-based approach. J Clin Pharm Ther 2009, $34: 207-213$
48. Reeves DJ, Bestul DJ: Evaluation of a single fixed dose of rasburicase $7.5 \mathrm{mg}$ for the treatment of hyperuricemia in adults with cancer. Pharmacotherapy 2008, 28:685-690.

49. Hutcherson DA, Gammon DC, Bhatt MS, Faneuf M: Reduced-dose rasburicase in the treatment of adults with hyperuricemia associated with malignancy. Pharmacotherapy. 2006, 26:242-247.

50. McDonnell AM, Lenz KL, Frei-Lahr DA, Hayslip J, Hall PD: Single-dose rasburicase $6 \mathrm{mg}$ in the management of tumor lysis syndrome in adults. Pharmacotherapy 2006, 26:806-812.

51. Trifilio S, Gordon L, Singhal S, Tallman M, Evens A, Rashid K, et al: Reduceddose rasburicase (recombinant xanthine oxidase) in adult cancer patients with hyperuricemia. Bone Marrow Transplant 2006, 37:997-1001.

52. McBride A, Lathan SC, Boehmer L, Augustin KA, Butler SM, Westervelt PW: A comparative evaluation of single fixed-dosing and weight-based dosing of rasburicase for tumor lysis syndrome. Pharmacotherapy, in press.

53. Vadhan-Raj S, Fayad LE, Fanale MA, Pro B, Rodriguez A, Hagemeister FB, et al: $A$ randomized trial of a single-dose rasburicase versus five-daily doses in patients at risk for tumor lysis syndrome. Ann Oncol 2011, Epub ahead of print.

54. Jeha S, Kantarjian H, Irwin D, Shen V, Shenoy S, Blaney S, et al: Efficacy and safety of rasburicase, a recombinant urate oxidase (Elitek), in the management of malignancy-associated hyperuricemia in pediatric and adult patients: final results of a multicenter compassionate use trial. Leukemia 2005, 19:34-38

55. Lee AC, Li CH, So KT, Chan R: Treatment of impending tumor lysis with single-dose rasburicase. Ann Pharmacother 2003, 37:1614-1617.

doi:10.1186/1756-8722-5-75

Cite this article as: McBride and Westervelt: Recognizing and managing the expanded risk of tumor lysis syndrome in hematologic and solid malignancies. Journal of Hematology \& Oncology 2012 5:75.

\section{Submit your next manuscript to BioMed Central and take full advantage of:}

- Convenient online submission

- Thorough peer review

- No space constraints or color figure charges

- Immediate publication on acceptance

- Inclusion in PubMed, CAS, Scopus and Google Scholar

- Research which is freely available for redistribution 